\title{
JOSE EMILIO PACHECO: RELECTURAS E HISTORIA
}

\author{
POR
}

\author{
ALICIA BORINSKY \\ Boston University
}

Como la literatura contemporánea de otros países latinoamericanos, pero con una intensidad mucho mayor y ciertamente idiosincrática, la de México encuentra su registro en una simultánea interrogación de sus razones de ser nacionales y su necesidad de formular figuraciones individuales.

Más allá de las obligaciones morales y políticas compartidas por los escritores con el resto del país, la literatura mexicana ha asumido, implícitamente, una concepción profunda de lo social al entretejer tramas que dicen lo nacional a través de su lectura. En este sentido, las obras de escritores tan dispares como Carlos Fuentes y Juan Rulfo terminan aproximándose. Lo privado se vuelve público; habla del lugar donde sucede y se confunde, inevitablemente en el destino o la interrogación de una colectividad ${ }^{1}$.

Esta tarea, cuyos mejores logros mucho se alejan del mero pintoresquismo para formular un sentido tentativo de México, su complicada historia y su enigmático paisaje, ha permeado la visión crítica de la literatura mexicana al punto de relegar a un plano menos discutido las obras de cuentistas y novelistas de inclinaciones que no tienen esta claridad de miras.

La literatura mexicana ha contado, desde hace varias generaciones, con escritores de ficción que trabajan de modos menos recuperables por las tendencias que he comentado. Entre los más importantes se encuentra José Emilio Pacheco.

En El principio del placer ${ }^{2}$ (1972) el relato -no incurramos en la discusión, vana, de si es un cuento largo o una novela corta - se centra en las relaciones entre

\footnotetext{
1 Esta meditación se encuentra también en ciertos momentos de todas las literaturas latinoamericanas, en la forma de obras de interés de reivindicación política y social y exploración de la identidad nacional. La literatura mexicana ofrece un continuo en este sentido que la convierte en un terreno privilegiado para pensar la realidad del país y su inserción en el mundo. La reciente polémica en torno a la obra de Carlos Fuentes es un ejemplo de la intensidad de lo requerido de los escritores y sus obras en México.

${ }^{2}$ Todas las citas se hacen de acuerdo con: José Enilio Pacheco, El principio del placer (México: Joaquín Mortiz, 1972).
} 
un muchacho con dominio del lenguaje y una joven de grandes atractivos físicos con mínimos indicios de "cultura". La narración es retrospectiva, el personaje es un estudiante secundario que nos ofrece su historia como parte de un diario íntimo que le han sugerido escribir en su escuela; desde el principio el lector percibe que está siendo incluido en una amistad cuyos cimientos son las confesiones que leerá en el diario:

\begin{abstract}
Pero, ¿a quién me estoy dirigiendo? Se supone que nadie va a leer este diario. Me lo regalaron para Navidad y no había querido escribir nada en él: tener un diario me parece asunto de mujeres, hasta me he burlado de mi hermana porque lleva uno y apunta muchas cursilerías: 'Querido diario, hoy fue un día tristísimo, estuve esperando en vano que me llamara Gabriel'; cosas así. De eso a los sobrecitos perfumados hay un paso, y qué risa les daría a los de la escucla enterarse de que yo también voy a andar con estas mariconadas (pp. 11-12).
\end{abstract}

"estas mariconadas ...", ¿por qué es que escribir un diario es una mariconada? Ciertamente no sólo el hecho de que se trate de una escritura que también hacen las niñas, sino algo más profundo: la atención brindada por el género mismo del diario a las relaciones interpersonales en la definición del muchacho que refiere lo que estamos leyendo. En su visión de las cosas, la intimidad alcanzada con el lector es un obstáculo para su ejercicio viril de la literatura y, sin embargo, paradójicamentc, lo que nos cuenta es un episodio que le ayuda a descubrir su naciente deseo por una muchacha. El medio de trasmisión de lo escrito se escinde, así, de lo referido al cuestionarse como vehículo, pero no olvidemos que el tono del texto está construido de modo de provocar una sonrisa en el lector que advierte que el muchacho que narra un acontecimiento que le ha pasado, lo hace con una ingenuidad que invita a condescendencia humorística en quien lee.

¿Qué quiere decir la sonrisa con que realizamos este comienzo de lectura? ¿Significa que la caracterización de la escritura de un diario como una mariconada es irónica? ¿Cuál sería el término de comparación?

Acaso la respuesta resida en una comparación con la no escritura en general. E1 principio del placer otorga el poder social y amoroso a unos personajes jóvencs claramente anti-intelectuales cuya fuerza parece residir en algo más allá de las palabras ${ }^{3}$ : la experiencia de la calle, la apariencia física, el triunfo de una complicidad excluyente. Cuando el adolescente narrador del relato nota su extrema vulnerabilidad y acepta su derrota amorosa, lo hace brindándonos su

\footnotetext{
${ }^{3}$ En otro trabajo ("On the Politics of Interlocution", de próxima aparición en la colección The Female Voice in Epistolary Literature, ed. E. Goldsmith; Massachussetts: Northeastern University Press) estudio este fenómeno tal como aparece en Puig y Derrida.
} 
recién adquirida filosofía, afín al tango: "Nadie tiene la culpa de que yo ignorara que todo es una farsa y un teatrito".

"Me decía todo esto interiormente para darme ánimos. Porque nunca en mi vida me sentí tan mal, tan humillado, tan cobarde, tan estúpido" (pp. 64-65). Su intento de venganza amorosa, de ajuste de cuentas, también falla haciendo al lector depositario de una experiencia cuyo único valor positivo reside en el desencanto "real" vuelto logro de escritura. Así, el personaje que se ha presentado en su vulnerabilidad, equiparando su necesidad de escribir a una "mariconada", cierra el diario con la pérdida de su objeto amoroso y la consecución de su amistad con el lector. El pacto con el lector en El principio del placer se hace a través de datos compartidos, el tácito entendimiento de que si escribir un diario indica debilidad, leerlo es lo mismo y la sospecha de que el resentimiento que el narrador siente con respecto a su propia ingenuidad suscitará la simpatía de quiencs, siendo adeptos a la lectura, son susceptibles a idénticos desdenes ${ }^{4}$.

Un interés parecido por reconstruir el pasado anima Las batallas en el desierto (1981), donde otra vez un narrador trata de reconstruir una temprana experiencia amorosa, esta vez más alejado temporalmente de su ocurrencia original: "Me acuerdo, no me acuerdo: ¿qué año era aquél? Ya había supermercados pero no televisión" (p. 9). No se trata de un diario, como en El principio del placer; la novela comienza directamente dando por sentado que la interlocución es posible, que el narrador debe recordar para alguien que ahora no está evocado — como en el texto anterior-como lector sino como escucha.

Si al final de El principio del placer el adolescente reafirma la posesión individual de su experiencia al desechar la interpretación de su mamá: "Si, en opinión de mi mamá, ésta que vivo es la 'etapa más feliz de la vida', como estarán las otras, carajo." (p. 66), en Las batallas del desierto, el narrador señala de entrada su pertenencia a una clara colectividad. El relato en primera persona del singular se alterna con un nosotros que simultáneamente busca definir una etapa de México y una manera de ser del narrador: "Unicamente los pobres seguían tomando

\footnotetext{
${ }^{4}$ Esta es la política sexual de la lectura en la obra. Para compartir la interpretación que el narrador-protagonista le da a su propia peripecia es necesario que el lector asuma una feminización que descarte, al mismo tiempo, los estereotipos sexuales ofrecidos por la novela. No es una aproximación al personaje femenino del relato; por el contrario, es el hallazgo de una manera de interpretar que acepta la sospecha de "mariconada" como rechazo de la grotesca diferencia femenino/masculino que estructura la experiencia "real" de los personajes en la ficción. Celebración, así, de la lectura como el romance realizado en la forma de un pacto entre lector y narrador.

${ }^{5}$ Las citas se hacen de acuerdo con: José Emilio Pacheco: Las batallas en el desterto (México: Joaquín Mortiz, 1981).
} 
tepache. Nuestros padres se habituaban al jaibol que en principio les supo a medicina. En mi casa está prohibido el tequila, le escuché decir a mi tío Julián. Yo nada más sirvo whisky a mis invitados: hay que blanquear el gusto de los mexicanos" (p. 12). Es en este contexto, mientras los niños en la escuela juegan a la guerra entre árabes y judíos, que el narrador, invitado a la casa de un compañero de escuela, se enamora de Mariana, su madre.

El narrador, de una familia numerosa, encuentra en el departamento de su compañero el orden y là elegancia (provista por Sears Roebuck, nos señala) que indican una atmósfera muy distinta a la de la propia; los rumores de la relación acaso no claramente legal - que unen a Mariana con el padre del amigo contribuyen a la sexualización de la figura de Mariana. Todo lo que la rodea adquiere un prestigio especial: su perfume, la manera en que prepara la merienda, sus ropas. Cuando el narrador, incapaz de contener su pasión, la confiesa, Mariana le respọnde en tono maternal, con los clisés que vuelven la humillación aún más evidente: "No quiero que sufras. Te esperan tantas cosas malas, pobrecito. Carlos, toma esto como algo divertido. Algo que cuando crezcas puedas recordar con una sonrisa, no con resentimiento. Vuelve a la casa con Jim y sigue tratándome como lo que soy, la madre de tu mejor amigo. No dejes de venir con Jim, como si nada hubiera ocurrido, para que se te pase la infatuation - perdón, el enamoramientoy no se convierta en un problema para ti, en un drama capaz de hacerte daño toda tu vida" (p. 38)

Otra vez, como en El principio del placer, el narrador ofrece a alguien que interpreta lo acaecido en términos que menosprecian la intensidad de sus sentimientos y quiere compartir con el lector la intensidad de una memoria del desastre. En esta obra, mucho más que en la otra, hay un intento de que el recuerdo de este momento amoroso coincida con la reconstrucción del México en el cual ocurrió. Los olores, sabores, consumos y reyertas políticas de la época subyacen en el relato $y$, al final, resultan tan inasibles por la memoria como la misma Mariana: "Demolieron la escuela, demolieron el edificio de Mariana, demolieron mi casa, demolieron la colonia Roma. Se acabó esa ciudad. Terminó aquel país. No hay memoria del México de aquellos años. Y a nadie le importa: de ese horror quién puede tener nostalgia. Todo pasó como pasan los discos en la sinfonola ..." (pp.6768).

El principio del placer y Las batallas en el desierto se detienen en la vulnerabilidad de un narrador cuyo fracaso amoroso lo prepara para una intimidad

\footnotetext{
${ }^{6}$ Las letras de bolero son el subtexto de esta obra y, en contrapunto con los elementos materiales ofrecidos por el jaibol y los muebles de Sears, contribuyen a dar una extendida arqueología de los sentimientos que animan el encuentro y pérdida del amor del personaje.
} 
especial con un lector, atraído por la falta de control sobre los hechos de quien le cuenta su experiencia. En estos dos libros recordar y padecer una pérdida son lo mismo; se quiere recordar para calificar un dolor, reconocer la incapacidad del lenguaje para modificar los hechos y aún para transmitirlos elocuentemente.

Como en un disco, los clisés del sufrimiento se repiten e intercambian, por eso la cursilería que acecha a toda evocación de cualquier amor, por eso el vínculo estrecho- con un lector que debe, ante todo, simpatizar y desechar el juicio negativo de la mariconada.

José Emilio Pacheco elabora una sostenida visión de lo perdido en su obra de ficción, uniendo la tensión retrospectiva de la interrogación histórica con la intimidad de una voz que se confiesa deseosa de amistad con quien lee.

En Morirás lejos ${ }^{7}$ (1967) la novela se plantea la sobrecogedora tarea de narrar las masacres de judios en los tiempos de Tito (en una versión de la versión de Flavio Josefo), durante el periodo de la Inquisición y en la época de la Segunda Guerra Mundial a través de las concertadas participaciones, entre otros, de un sobreviviente de los campos de exterminio nazis, un torturador y un narrador omnividente (como se lo llama en el texto). Es aquí donde aparecen por primera vez en la obra de Pacheco las figuras de un dolor y un odio que no pueden ser contenidos por la literatura. Al mismo tiempo, es imperioso re-escribirlas para que la memoria las siga reteniendo y sepa que, en las palabras del personaje sobreviviente Ludwig Hirszfeld: "Todo el misterioso proceso que convierte a un hombre en asesino consiste en una transformación del mismo orden. En el alma humana se produce un minimo reajuste de conceptos y sentimientos, pues hay que despojar a la futura víctima de todos los atributos de la humanidad para conferirle los de una especie repulsiva: una chinche, una rata o un piojo" (p. 41).

En El principio del placer y Las batallas del desierto flirteamos con el mal gusto y la vulnerabilidad de quien se dirige a nosotros; Morirás lejos señala que otra repetición es posible y, por eso, en el registro íntimo de su factura nos habla al oído para contarnos nuevamente aquello que ya sabemos aunque nunca demasiado bien, con la intención de impedir su recurrencia.

Una intensa búsqueda ética sin facilidades maniqueas permea este temprano c importante libro de Pacheco y nos señala avenidas de lectura para el resto de sus preocupaciones en torno a la confección de re-escrituras.

\footnotetext{
${ }^{7}$ Las citas se hacen de acuerdo con: José Emilio Pacheco, Morirás lejos (México: Joaquín Mortiz, 1967). Hay una nueva edición disponible de la novela (Joaquín Mortiz, 1986).
} 


\section{EL TESTIGO: LA TRAMPA DE SU TESTIMONIO}

Las dos obras comentadas al principio presentan, con mayor o menor explicitación, una escena básica: un narrador que otorga la información al lector al mismo tiempo que se convierte, él mismo, en personaje afectado por el relato. Este recurso, ubicuo en nuestra literatura desde Horacio Quiroga, adquiere en Pacheco un perfil propio. El lector debe someterse a las manipulaciones de textos que exigen una respuesta de índole ética. No se trata de la indignación frente a condiciones sociales injustas sino de un pacto realizado en la intimidad con el narrador cuya anécdota, referida con la transparencia de una conversación, parece borrar las barreras erigidas por la escritura.

¿Cuáles son las condiciones creadas por esta situación?. ¿Qué obligaciones surgen con la lectura? Los testimonios de Las batallas en el desierto y El Principio del Placer necesitan un lector que sea, también, compañero de viaje. La función de salvar al narrador de sus penares se realiza en cada momento de la lectura de estos volúmenes en la forma de condena del mundo de vulgarización machista del amor (El principio del placer) o la incomprensión de los mayores en el contexto de un México corrupto con injustas diferencias sociales (Las batallas en el desierto).

De este modo, los requisitos del testimonio son claramente cumplidos por el lector ayudado por la vulnerabilidad de quien narra. Esa vulnerabilidad es el vehículo de la realización de la respuesta ética ${ }^{8}$ ya que al compartir el secretơ de la debilidad de quien le brinda el relato, el lector asume la energía que a él le falta y es capaz de hacer un ajuste de cuentas con la historia por medio de su propia participación en el texto. Al lector le son legados el simulacro de acción sugerido por la respuesta indignada que Mariana da a su amante en Las batallas en el desierto y la defensa de la literatura como medio de seducción y verdadero mérito en $E l$ principio del placer.

En la intimidad de estas narraciones amorosas se despliega un campo polémico acerca de la historia mexicana y los mecanismos del amor; la vulnerabilidad del narrador - personaje con respecto a sus intereses explícitos en los relatos cambia de signo en la celebración de su acuerdo çon quien lee su testimonio. Debilidad, así, como condición para una amistad que la convierte en su opuesto.

\footnotetext{
${ }^{8}$ Dificultad del testimonio: ¿hay neutralidad posible o podemos aducir que cada hecho conlleva la necesidad de una respuesta ética? ¿Es esa respuesta producto de lả interpretación o la realidad misma se ofrece a nuestra percepción munida de los resortes que nos permiten evaluarla? La noción en este libro de Pacheco es un claro rechazo de la impasibilidad frente al mal.
} 
El interés de José Emilio Pacheco por los materiales históricos no se da en la forma de control, apropiación. Por el contrario, es ocasión para solicitar del lector las armas que puedan convertir a la memoria en apreciación crítica.

Morirás lejos, de factura muy distinta, crea mecanismos de acercamiento a través de una narración entrecortada, con documentos "reales" y "ficticios". El padecimiento judío a través de la historia y la indiferencia de quienes, en el presente de México, eluden hacerse cargo de este legado plantean la pregunta con respecto a la escritura del dolor: ¿qué significa saber?

Despleguemos el interrogante: ¿qué se sabe cuando se conoce el dolor? ¿qué ocurre con las escenas repetidas y documentadas en variados textos cuando son retransmitidas en un presente aparentemente distinto? ¿se puede salvar la distancia con el pasado para salvar, simultáneamente, la actualidad de ese pasado en una percepción que opere de barrera contra el horror?

En una América poblada, desde el descubrimiento, por la galería de quienes escapaban de la intolerancia europea, recortada por la esperanza y el padecimiento, el olvido ensaya sus poderosas coreografías. Morirás lejos, al hacernos participar en la dificultad de su escritura en tanto testimonio, nos obliga a tomar parte en el ejercicio del recuerdo. Es un recuerdo sin complacencias: no se aplaude a la literatura por poder hacerse cargo de la realidad que pretende nombrar ni se celebra la debilidad de las víctimas. La novela transcurre en una suerte de tartamudeo temporal que sugiere una lectura que encuentre la articulación necesaria entre las distintas experiencias, que las selle y deje atrás. Pero la falta de resolución de cómo contar lo que se nombra hace que el problema se vuelva urgente como tal. El lector lucha por completar las oraciones del tartamudeo, visualizar los espacios evocados, dar sentido dándose sentido a sí mismo dentro de la lectura.

Paradójicamente, y, a pesar del título, lo remoto no está a una distancia prohibitiva en Morirás lejos; la verdadera distancia es la que existe entre los que caen y caerán con respecto a quienes cuentan y leen. Agónica, tratando de cancelarse y estudiando los límites de su posibilidad, esta distancia sugiere que la reescritura es siempre necesaria porque nunca habrá testimonio completo. Ese resto, ese suplemento que convierte en inadecuado todo discurso, devuelve peso y realidad al dolor; nos torna testigos insatisfechos, lectores activos. 
